$\mathbf{R}_{\text {ESEARCh }} \mathbf{P}_{\text {APER }} \longrightarrow \frac{\text { FOOD SCIENCE }}{\text { RESEARCH JOURNAL }}$

\title{
Effect of storage on acceptability and nutrient content of iron rich toffee
}

\author{
T.N. Khan and J.P. Nerlekar
}

\begin{abstract}
Iron rich toffees were prepared from, Rajkeera (Amaranthus paniculatus) and Bengal gram leaves (Cicer arietenum) powder. The prepared toffees were stored in airtight glass containers at room temperature for a period of six months. The periodical acceptability was evaluated at $0,1,2,3,4,5$ and 6 months of storage period. The nutrient content and microbial count of toffees was determined at 0,3 and 6 months of storage period. The iron content of toffee $\mathrm{R}$ is $31.8 \mathrm{mg} / 100 \mathrm{~g}$ and for toffee RB $28.30 \mathrm{mg} / 100 \mathrm{~g}$. The results of mean acceptability scores of organoleptic characteristics of iron rich toffees stored for six months showed that as the period of storage increased all the organoleptic scores decreased. Similarly the nutrient content was highest at initial stage and decreased for 3 and 6 months of storage except moisture. The results of storage study indicated that as the period of storage increased organoleptic characteristics and nutrient content decreased while microbial content increased.
\end{abstract}

Key Words : Storage, Acceptability, Nutrient content

How to cite this article : Khan, T.N. and Nerlekar, J.P. (2018). Effect of storage on acceptability and nutrient content of iron rich toffee. Food Sci. Res. J., 9(1): 58-60, DOI : 10.15740/HAS/FSRJ/9.1/58-60. 